\title{
Erratum to: A Novel Time/Temperature Approach to Sous Vide Cooking of Beef Muscle
}

\author{
Massimiliano Rinaldi $^{1}$ - Chiara Dall'Asta ${ }^{1} \cdot$ Maria Paciulli $^{1} \cdot$ Martina Cirlini $^{1}$.

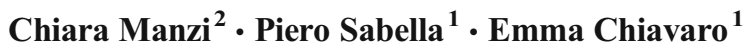

Published online: 26 October 2015

(C) Springer Science+Business Media New York 2015

Erratum to: Food Bioprocess Technol (2014), 7 (10):2969_ 2977

DOI 10.1007/s11947-014-1268-z

The erratum regards the addition of one author, Piero Sabella, to the previous list of contributors. Piero Sabella's contribution was partially given for the execution of the colour and texture analyses.

The new list of authors will become Massimiliano Rinaldi, Chiara Dall'Asta, Maria Paciulli, Martina Cirlini, Chiara Manzi, Piero Sabella, Emma Chiavaro as presented above.

The online version of the original article can be found at http://dx.doi.org/ 10.1007/s11947-014-1268-z.

Massimiliano Rinaldi

massimiliano.rinaldi@unipr.it

$\triangle$ Emma Chiavaro

emma.chiavaro@unipr.it

1 Dipartimento di Scienze degli Alimenti, Università degli Studi di Parma, Parco Area delle Scienze 59/A, 43124 Parma, Italy

2 ASSIC, Associazione per la Sicurezza Nutrizionale in Cucina, via Arezzo 29, 00161 Roma, Italy 